\title{
GSM - Based Vehicle Information Management System
}

\section{(Roadmap for Law Enforcement Agencies in Managing Information Related to Vehicle Security in Developing Country)}

\author{
* Oladimeji A. Isaac ** Dr. Onyesolu M.O \\ *** Yusuf Husaini Amana \\ **Department of Computer Science, Faculty of Physical Science, Nnamdi Azikiwe University, \\ Awka *, *** Department of Computer Science Education,Aminu Saleh College of Education, Azare Bauchi State,
}

\begin{abstract}
Insecurity been a major challenge that the entire world are battling with, each with different security issues/problems. Crime rate in our society these days is becoming frightening as vehicles are been used for committing crime and research shows that perpetrator of this acts make use of stolen vehicles snatched at gun points which is causing damages to live and properties. The Nigerian vehicle inspection system adopted a manual method that involves the use of screening papers for prove of ownership which is prone to error and very easy to manipulate. There are various methods of scheming the inspectors since lots of manipulation can be done on paper. This study seek to designed a GSM-based vehicle security information management system that will sending a short message to a particular designated shortcode, which in turns bring back all necessary information needed by the vehicle inspection team to verify the authenticity of the vehicle ownership. The system is designed using PHP and MYSQL server which is used in storing data being captured, PHP is an easy to learn language, open sour ce, has large base of users and developers (community), it has larger database support and also has multiple platform support. If the system is implemented with the right technology it deserves, the rate at which vehicles will be stolen at gun-points or crime rate will be reduced if not totally eradicated and also shows that GSM is viable as a platform for managing the process of inspection of vehicles.
\end{abstract}

\section{INTRODUCTION}

In everyday fast insecure world, the need to maintain a well secured vehicle inspection is increasingly significant and increasingly complicated. Presently, terrorism attacks are been spread from states to states, from countries to countries and thus, a proper security approach needs to be adopted by the government in order to protect vehicles and their owners. The perpetrators of this act make use of stolen vehicles and abandon them after using them.. Most of these terrorists make use of stolen cars (government or individual owned) to perpetuate their acts. Sometimes, when these vehicles are stolen, their plate numbers are changed and later abandon these vehicles or even sell them to unknown persons, which in most cases cause problems to the buyer of such vehicles.

The Motor Vehicle Inspection Unit is charged with the responsibility of ensuring the provisions of the Traffic Act and subsidiary rules relating to Motor Vehicle examination such that all vehicle owners comply to these laws in order to minimize road accidents (Omondi, 2009). Checking if a vehicle is roadworthy before driving, ensuring that any equipment, fittings and features required are present and serviceable, not driving a vehicle if faults are present or developed, ensuring that all are actions taken when driving a vehicle are all these checks that will help to ensure one's own safety and that of any passengers or other road users. Several law enforcement agencies are involved in vehicle checking in order to combat crime.

\section{BACKGROUND STUDY}

In developing countries, Nigeria for instance, vehicle inspection is posed with problems of fake particulars issued to unsuspecting motorists by fake licensing officers; improper checking procedures by the law enforcement agencies due to weak inspection mechanism system put in place. These exercises lead to confrontation between the citizen and the law enforcement officers. The current system sabotages the effort of government in revenue driving, as most vehicles are not duly registered. This cannot even be detected during inspection. Managing Vehicle crime related cases are difficult due to weak inspection mechanism in place. Therefore, a vehicle inspection system which is based on the Global System for Mobile Communication (GSM) technology that effectively allows law enforcement officers to access vehicle information from a remote area or from any desired location provided that there is network connectivity is apt.

The current Vehicle Security Information Management System is done manually. Once a vehicle has been flagged down by law enforcement officer responsible for vehicle inspection, he/she demands for the vehicle's particulars (supposed vehicle registration documents).These particulars contain details about the vehicle i.e. the engine number, chassis number, and the maker of the vehicle, year of the production, colour and model of the vehicle.

He or she checks the documents, one after another trying to ascertain, check and determine the authenticity of the documents. Most times identifying fake from genuine vehicle documents becomes problem as there is no any security measure put in place to checkmate the authenticity, rather than official stamp and government logo(coat of army ) which can be counterfeited. The existing system is characterized but not limited to the following inefficiencies. 
i. Law enforcement duties overlapping.

ii. Both law enforcement agency and citizen in confrontation during vehicle inspection exercise, as citizen most times doesn't even know exact vehicle particular to be collected.

iii. Authentications of vehicles registration particulars become difficult in current system.

iv. The current system makes retrieval of information very difficult because of the large volume of file one has to sort through to retrieve or have access to one's file.

v. Lot of time is devoted to the filing of duplicates in logical way. For easy retrieval of information.

vi. The current system lacks a database for the storage of files which make those files to occupy physical storage space.
The aim of this study is to design a framework for Vehicle Security Management Information System, which will serve as roadmap or guide for law enforcement agencies in managing information related to vehicle security.

\section{METHODOLOGY OF THE PROPOSED SYSTEM}

The new system suggested the request of the vehicle information can be done through any network of cellular phones. The law enforcement officer can access the vehicle information using his/her cell phone. The officer can inquire vehicle information via SMS by entering a verification code on his or her mobile phone. Only the main administrator can add, edit, view and delete vehicle information. The system link and obtain vehicle information from already existing database of law enforcement agencies. The device used in the system is for inquiry and request only. The block diagram of the proposed system is shown in figure below:

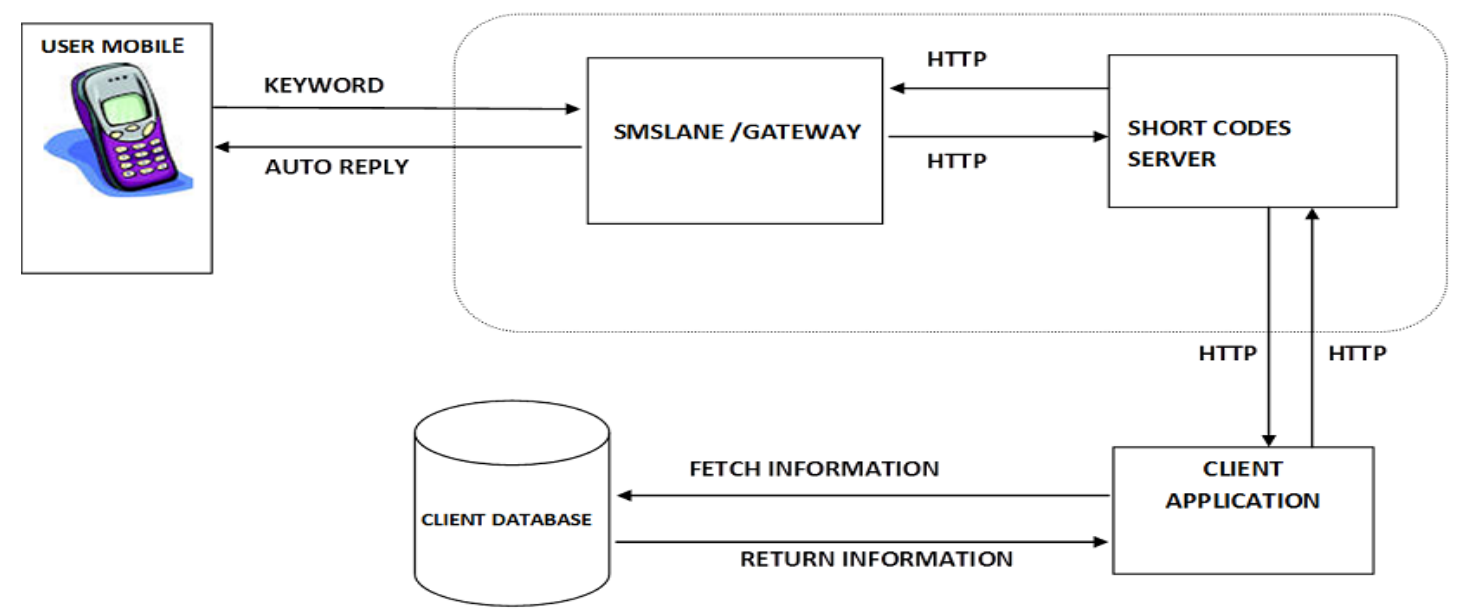

(Figure 1: framework)

DATA FLOW DIAGRAM OF THE FRAMEWORK

This is a graphical representation of the flow of data through an information system. It mainly reveals relationships between entities by showing what data come from where, where it is going to, as well as where it will be stored. The processes timing is not usually include in data flow diagrams. Meanwhile, the Data Flow Diagram of the New System is shown in figure 2 below.

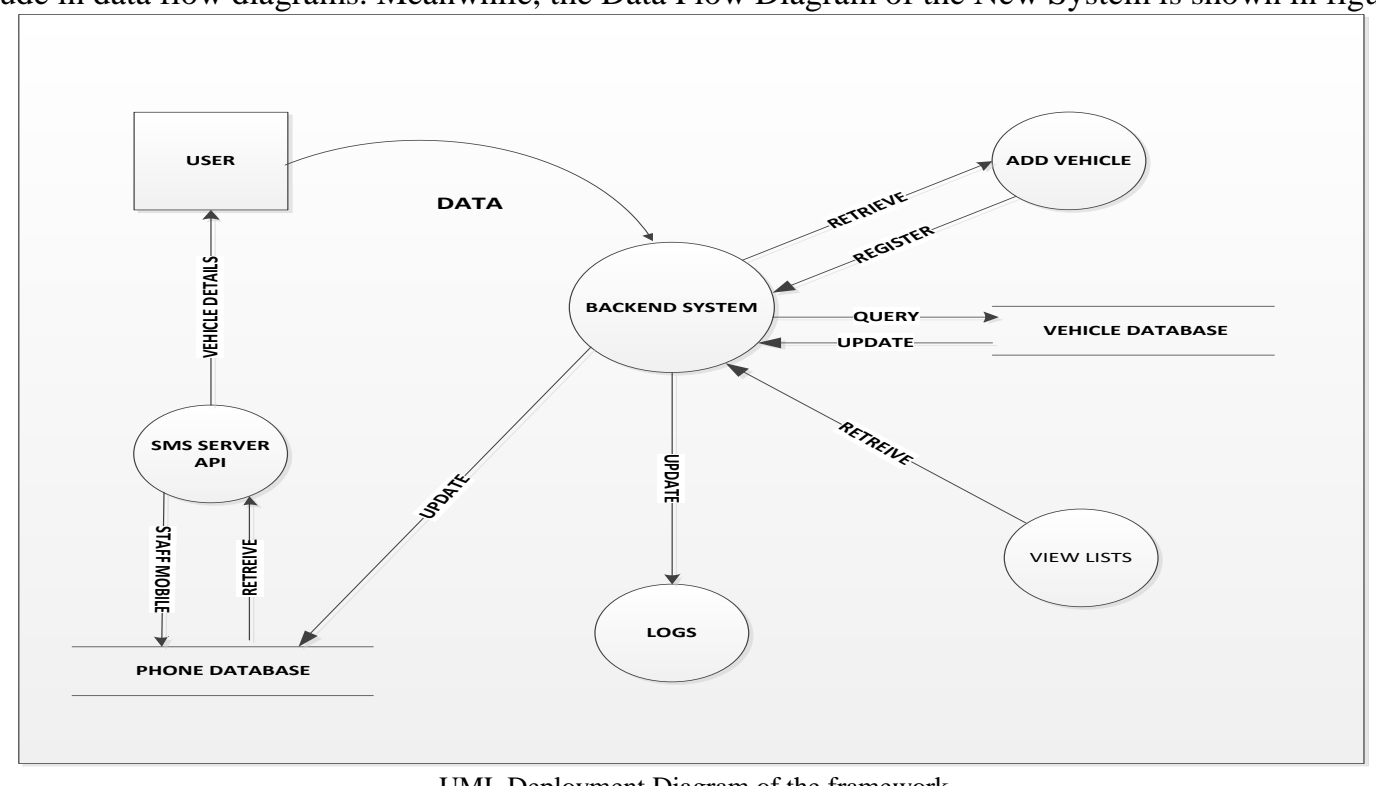

UML Deployment Diagram of the framework 
The UML deployment diagram of the new system is shown in figure 3.

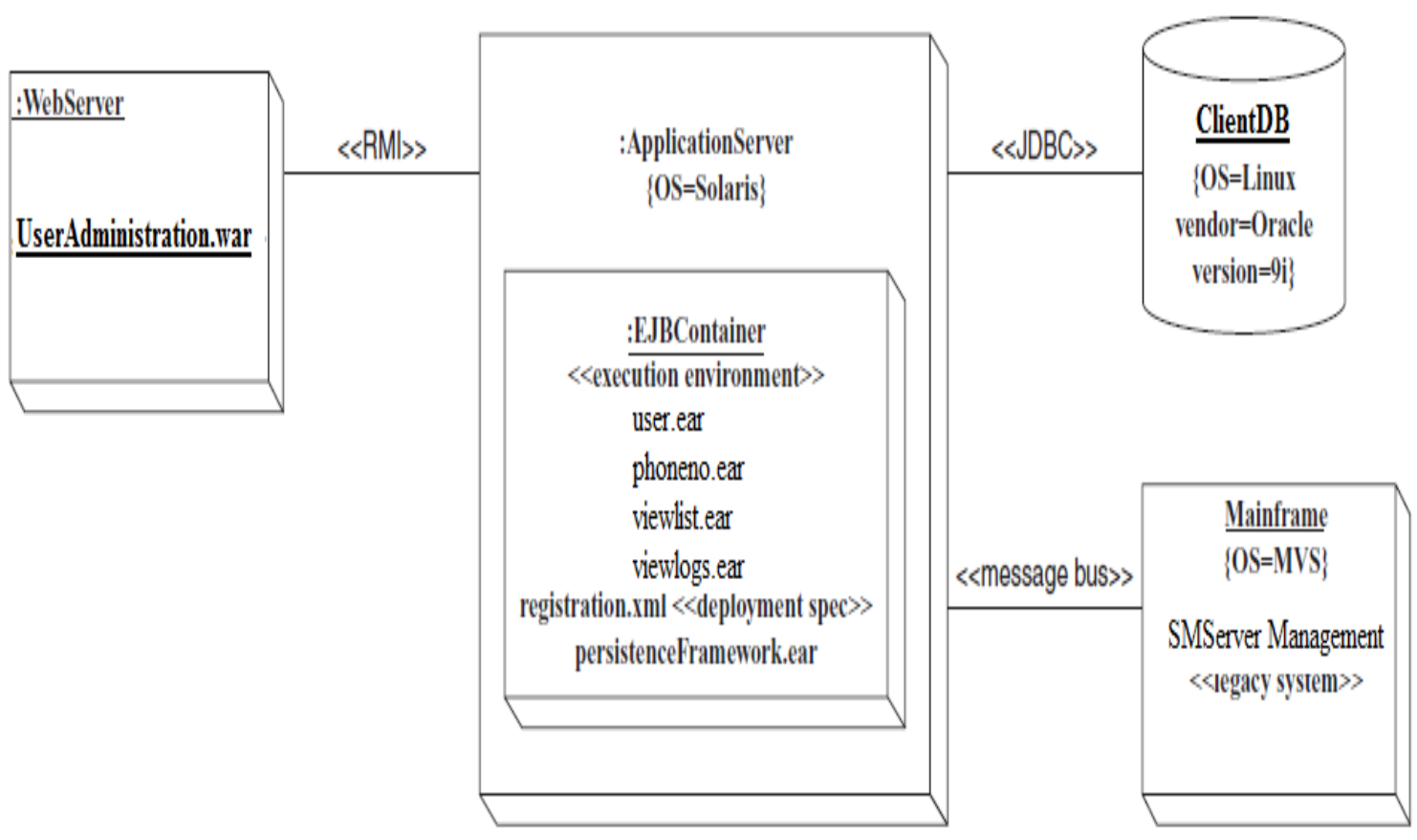

( Figure 3: UML Deployment Diagram of the proposed System)

\section{Objectives of the Design}

The design phase is very crucial and must be in compliance with stated objectives, they are:

i. Designing a cost-effective, simple and easy-to-use system for vehicle security management and vehicle verification information access. This system will put at the finger tip, access to vehicle information for the purpose of verification by specified individual allowed to access the system.

ii. Implement a short-code based communication between the system and the application. The whole process will convey information to and from the system to the end user.

iii. Implement an intuitive and administratively efficient system that will revolutionize the traditional approaches to vehicle verification and information access by the end users.

iv. Provide an easy and automatic procedure for access to vehicle information by end users.

This study was made to find out how the use of GSM. system will lessen the time spent in getting accurate vehicle information for the purpose of verification and investigation. This system will also help in vehicle tracking process especially crime related ones. The system can recognize the person (Law Enforcement Officer) involved in a particular vehicle verification.

\section{CONCLUSION AND FUTURE WORK}

It is a well-known fact that insecurity is what most of the developing nation spend their affluence on. Many researchers have tried to have a lasting solution to these problems by try to profound solution in different ways in like manner of this study. GSM-Based Vehicle Security Information Management System is widely available means of vehicle inspection for most laws enforcement agency. The use of this medium enhances easy access to vehicle owner's information via mobile phone. The system designed which make used of a SMS and shortcodes technology automated program that handle the response and typically requires the sender to start the message with a command word or prefix. This system uses a 2-tier level verification system involving the law enforcement agency's mobile phone number. The GSM- Based Vehicle Security Information Management System tries to approach vehicle inspection from the point of social interaction between the vehicle users and inspection officers to improve the security to a certain level. The existing system needs the vehicle user to produce the registration documents, while in the new system the plate number is only required. With the used of this system the issues of vehicle be stolen or collect at gunshot will be reduced if not totally eradicated.

This study will go a long way to eliminate fraud associated in vehicle registration if well applied. It is therefore recommended that the government should adopt the system in vehicle registration information access exercise and extend Autoreg registration to Local Government liaison offices to maintain a central database of all registered vehicles in Nigeria. The Nigerian Police and the Road Safety Commission should as well adopt the system in tracking vehicle crime related offences.

This study had proffer solution on how to get timely information on vehicle for the purpose of on spot inspection and crime investigation, thereby reduce the long process of on spot vehicle inspection, the inconvenient, tiresome and at some instance are time consuming and purpose end not been achieved. Most time, the exercise leads to confrontation between the citizen and the law enforcement officers. 
The researcher strongly suggests further research into others arms of vehicle security information management system in Nigeria from point of purchase to the last stage of registration. This will go a long way to establish a healthy vehicle security information management system in Nigeria.

\section{REFERENCES}

[1] Oladimeji A. Isaac (2016). Design and Implementation of GSM Based Vehicle Security Management System, A Project Submitted to Department Of Computer Science, Faculty Physical Science, Nnamdi Azikiwe University, Awka, in Partial Fulfillment Of The Requirement For The Award Of Masters Of Science In Computer Science ( unpublished).

[2] Omondi Martin (2009): The motor vehicle safety and inspection. Power point presentation, www.unep.org. retrieved 2013 